\title{
Public Health Dilemmas Concerning a 2-year old Hepatitis-B Carrier - Response
}

\author{
Marcel Verweij • Jim van Steenbergen
}

Received: 30 January 2008 / Accepted: 30 January 2008 / Published online: 13 February 2008

(C) The Author(s) 2008

The public health physician is concerned about the possibility that, at a nursery, this boy would have close contact with other children and might infect them with hepatitis B virus (HBV).

HBV infection in children is often asymptomatic, and acute disease with severe complications is rare. However, children often become chronic carriers after infection, which may lead to cirrhosis and liver cancer. HBV carriers also remain life long sources of infection to others and hence contribute to the spread of disease.

HBV is mainly spread via blood and semen. Transmission through saliva, though unlikely, is certainly possible, especially where the boy shows a high HBV viremia [1]. The risk of transmission in day care is low, but has been reported and confirmed by genotyping [2-6]. The theoretical routes of transmission are direct through small wounds and, more important, by child bites. Indirect transmission is also possible through the sharing of utensils including toothbrushes, and, to a lesser extent, the sharing of toys that children may put in their mouth.

Only very few countries with low incidence and prevalence of HBV infection, have not yet included

M. Verweij $(\bowtie)$

Ethics Institute, Utrecht University,

Utrecht, The Netherlands

e-mail: m.f.verweij@uu.nl

J. van Steenbergen

Centre for Infectious Disease Control,

Bilthoven, The Netherlands hepatitis B in their universal childhood vaccination program. Universal vaccination prevents (most) day care transmission. This case occurred in The Netherlands, and as The Netherlands does not have a universal HBVvaccination program, one could assume that most of the children in this nursery would be susceptible to HBV infection.

However, there seems to be no scientific consensus that the vaccine does offer full protection against the G145R-HBV-mutant. While animal studies suggest that the vaccine does protect against this mutant [7] there remains ongoing uncertainty regarding the effectiveness of the vaccine [8].

The case description presents several policy options: preventing the child from attending the nursery; allowing him to go but with strict hygienic measures at the nursery; and offering vaccination to all other children at the nursery. All these possibilities may be detrimental to the child's welfare because he will be treated differently by care-givers and other parents. And even if day care staff and other parents are not informed which child is the source of risk, it may be difficult to keep it a secret. This would be more so if care-givers are informed and subsequently are more attentive to possible risk-contacts of the boy. Other parents may find out about the identity of the child and try to avoid contact between him and their own children. Moreover, the theoretical possibility that this child may be infected with a virus against which there is less protection could easily lead them to overestimate the risks of infection. 
On the other hand, if there are legal possibilities to refuse admission to the nursery, this might be even more harmful to the wellbeing of the boy and its parents. For if the boy's parents are told that the risks of infection are too high to allow their child admission to a nursery, this will not only reduce the opportunities for their child to meet other children, but also make it more difficult for them to combine their work responsibilities (hence income) and the care for their child. It also imposes a moral responsibility on the parents to avoid similar contacts with other children at home or in the neighborhood, for if there are sufficient reasons to avoid contacts in a nursery, shouldn't parents see to it that similar contacts will not occur when their child is playing with friends in the neighborhood?

In short, special measures to prevent disease transmission create clear burdens for the child and her/his parents. We assume that the importance of being able to play freely with other children is essential to the psychological and social development of any child. Measures that explicitly aim at restricting such contacts, or which may lead other parents and children to avoid such contacts, can only be morally justified if there is a clear risk that others will be harmed. In this case, the risk may be too remote to justify measures of control that will almost certainly have negative effects on the well being of this boy and his parents.

First, even though the boy has a high viral load, the risk of transmission of the virus through (ingestion of) saliva is very small. Hence, one may question whether care givers at the nursery really need to be extra attentive about toys or food which the boy takes in his mouth, and which might be taken by others afterwards. Such special attentiveness (i.e. different from normal hygienic care - which should occur anyway) may not have any significant effect on the possibilities of infection. Moreover, in The Netherlands as there is no hepatitis admission screening for children attending day care, one may reasonably ask whether other (unknown) carrier children might pose a similar, or higher, risk of transmission. Special (and potentially burdensome) measures and attentiveness towards the boy in this case might then be unfair. This implies that there is no reason to inform the professionals in the nursery about the specific risks with respect to this boy.
Second, the risks of transmission through biting or being bitten are more important, as this may involve blood-saliva contacts. However, such a possibility of infection only occurs if a bite is sufficiently severe that skin is broken, which happens infrequently.

With respect to a child with HBV in a nursery, the Dutch Centre of Infectious Disease Control suggests that each child should be assessed to ascertain the specific risks of infection. If the index child is a known 'biter,' or has other transmission prone behavior, it may be justified to offer vaccination to all other children in the nursery (this approach only makes sense for countries like The Netherlands where children do not receive vaccination against HBV).

But assuming that the public health physician believes that there is an increased risk of infection that would warrant offering $\mathrm{HBV}$ vaccination to other children, how does one account for the fact that this boy carries the G145R-HBV-mutant, and HBV vaccination may have uncertain protective effect against this particular genetic variation? If parents are told that $\mathrm{HBV}$ vaccination may be less effective against this strain of $\mathrm{HBV}$, this may lead to extreme stigmatization: parents not allowing their children to be near the "infected child." If parents and professionals are not informed about the identity of the child, this might lead to protest and suspicion, leaving the parents of the infected boy, and the child himself, in an impossible position. It is also possible that some parents, knowing that childhood HBV is more common in certain groups, including immigrants or adopted children, may suspect children simply because they come from 'high-risk' populations.

While available evidence suggests that HBV vaccination offers less protection against G145R-HBV, there is no evidence that it offers no protection. But vaccination may not offer complete protection against 'normal' wild type virus either. Hence it is questionable whether the response to children such as the boy in this case should be any different to the public health response to other children infected with the 'normal' hepatitis B virus. It is impossible to completely avoid the risk of HBV infection. Moreover, striving to avoid any possible risk - or informing parents about even the remotest risk - would be detrimental to the welfare of HBV-carriers and their families. 
Open Access This article is distributed under the terms of the Creative Commons Attribution Noncommercial License which permits any noncommercial use, distribution, and reproduction in any medium, provided the original author(s) and source are credited.

\section{References}

1. Van der Eijk, A. A., Niesters, H. G., Gotz, H. M., et al. (2004). Paired measurements of quantitative hepatitis B virus in saliva and serum of chronic hepatitis patients: Implications for saliva as infectious agent. Journal of Clinical Virology, 29(2), 92.

2. Fisker, N., Georgsen, J., Stolborg, T., Khalil, M. R., \& Christensen, P. B. (2001). Low hepatitis B prevalence among pre-school children in Denmark: Saliva anti-HBc screening in day care centres. Journal of Medical Virology, 68(4), 500504.

3. Shapiro, C. N., McCaig, L. F., Gensheimer, K. F., Levy, M. E., Stoddard, J. J., Kane, M. A., et al. (1989). Hepatitis B virus transmission between children in day care. Pediatric Infectious Disease Journal, 8(12), 870-875.

4. David, E., McIntosh, G., Bek, M. D., Burgess, M. A., Isaacs, D., \& Cossart, Y. E. (1996). Molecular evidence of transmission of hepatitis B in a day-care centre. Lancet, 347 (8994), 118-119.

5. Broholm, K. A., Sjödin, L., Backlund, I., Johansson, B., Norder, H., \& Magnius, L. (2001). Hepatitis B outbreak in a day care center affected several families. It could have been prevented by vaccination of all children. Lakartidningen, 98 (19), 2337-2338, 2341-2342 (Swedish).

6. McIntosh, E. D., Bek, M. D., Cardona, M., Goldston, K., Isaacs, D., Burgess, M. A., et al. (1997). Horizontal transmission of hepatitis B in a children's day-care centre: A preventable event. Australian and New Zealand Journal of Public Health, 1997, 21(7), 791-792.

7. Ogata, N., Cote, P. J., Zanetti, A. R., et al. (1999). Licensed recombinant hepatitis $B$ vaccines protect chimpanzees against infection with the prototype surface gene mutant of hepatitis B virus. Hepatology, 30(3), 779-786.

8. Zuckerman, A. J. (2000). Effect of hepatitis B virus mutants on efficacy of vaccination. Lancet, 355, 1382-1384. 